\title{
A comparative study between the effect of $17-\beta$ estradiol and angiotensin converting enzyme inhibitor on osteoporosis in ovariectomized rats
}

\author{
Mona M. Allam and Noha I. Hussien \\ Department of Physiology, Faculty of Medicine, Benha University, Benha, Egypt
}

\begin{abstract}
Osteoprotegerin (OPG) and receptor activator of nuclear factor-kappa B ligand (RANKL) have been revealed in the pathogenesis of primary osteoporosis and other metabolic bone diseases. This study was designed to assess the effect of $17-\beta$ estradiol (E2) treatment and angiotensin converting enzyme inhibitor (ACEI), captopril, on osteoporosis induced by ovariectomy in rats and discussing the role of OPG/RANKL ratio in their action. Thirty two adult female rats were divided into four equal groups. Group I: control group, Group II: ovariectomized (OVX) non treated group, Group III: OVX rats treated with E2, Group IV: OVX rats treated with captopril. OVX rats showed a significant decrease in serum $\mathrm{Ca}^{2+}$ and OPG levels with significant increase in serum RANKL, osteocalcin, alkaline phosphatase activity and urinary hydroxyproline levels. Treatment with captopril as well as E2 led to a significant improvement in bone markers levels with a significant increase in OPG/RANKL ratio. Image analysis technique revealed that there was a significant improvement in cortical bone thickness (CBT) and mean trabecular bone density (TBD) in OVX rats treated with either E2 or ACEI. So, we can conclude that the protective effect of E2 and ACEI on osteoporosis may be mediated by influencing OPG/RANKL signaling.
\end{abstract}

Keywords: Osteoporosis $-17-\beta$ estradiol - Captopril - OPG/RANKL

\section{Introduction}

Osteoporosis being one of the major complications affecting the postmenopausal women is a systemic skeletal disease that is characterized by low bone mass and deterioration of bone tissue with an associated increase in fragility and susceptibility to fractures (Kaczmarczyk-Sedlak et al. 2012). In Egypt, it has been calculated that $28.4 \%$ of postmenopausal women have osteoporosis (Mohy 2011).

The ovariectomized (OVX) rat model remains the most popular choice that represents some of the most important clinical features of postmenopausal bone loss (Muthusami et al. 2005).

It's well known that the estrogen exerts a direct protective effect on the bone through its receptors; it decreases the rate of production of osteoclasts, their activity and their survival and exerts an anabolic effect on osteoblasts. In addition the

Correspondence to: Noha I. Hussien, Department of Physiology, Faculty of Medicine, Benha University, Benha, Egypt

E-mail: drnohaibrahim79@gmail.com production and activity of some pro-inflammatory cytokines is known to be regulated by estrogen, these cytokines such as interleukin-1, tumor necrosis factor (TNF) alpha and nuclear factor-kappa B ligand (RANKL) are known to stimulate bone resorption and inhibit bone formation (Riggs et al. 2002).

RANKL is a TNF family member produced by osteoblasts lineage cells, it is essential for differentiation of the cells involved in bone resorption, the osteoclasts. It exerts its effects through binding to its receptor (RANK) on osteoclast precursor cells. Such binding results in activation of osteoclasts and their survival. Osteoblasts also produce osteoprotegerin (OPG), a potent inhibitor of osteoclast formation. OPG reduces the production of osteoclasts by inhibiting the differentiation of osteoclast precursors into osteoclasts and also regulates the resorption of osteoclasts in vitro and in vivo. As OPG binding to RANKL blocks the RANKL-RANK interaction. This has the effect of inhibiting the differentiation of the osteoclast precursor into a mature osteoclast (Coetzee and Kruger 2004). The RANKL/RANK/ OPG system has been implicated in various skeletal and immune-mediated diseases characterized by increased bone 
resorption and bone loss, including several forms of osteoporosis (postmenopausal, glucocorticoid-induced, and senile osteoporosis) and the OPG/RANKL ratio is considered a reliable marker of the differentiation state of the osteoblast and osteoclast (Hofbauer and Heufelder 2000).

Hormone replacement therapy (HRT) is used widely to overcome the basic disorders associated with menopause; however, its use revealed several complications including increased risks of breast, endometrial and ovarian cancers (Rossouw et al. 2002).

The renin-angiotensin system (RAS) is found not only systemically but also locally in several tissues. Recent studies showed that the components of RAS, such as renin, ACE, and angiotensin II (Ang II) receptors, were expressed in the bone. Recent findings showed RAS to play an important role in bone tissue suggesting a detrimental effect of (Ang II) on bone. It was indicated that Ang II is a potent stimulator of osteoclastic bone resorption. This has led to the theory that ACEI and angiotensin receptor blockers may have an indirect effect on bone mineral density and fracture risk (Donmez et al. 2012).

Our study was designed to investigate a possible effect of captopril, an angiotensin converting enzyme inhibitor (ACEI), on bone markers in estrogen deficiency-induced bone loss by comparing this protective effect to $17-\beta$ estradiol (E2) supplementation in ovariectomized rat models and to discuss the role of OPG/RANKL ratio as a possible mechanism of action. This could answer a very important question, if ACEI used for treating hypertension has a protective effect on bone loss caused by estrogen deficiency in menopausal female or not? To avoid the side effects of both estrogen and ACEI used for treatment of osteoporosis and hypertension that are commonly present together in menopausal females by avoiding using the two drugs at the same time.

\section{Materials and Methods}

The present study was carried out on adult 32 Wistar albino female rats with an average age of 4-5 months weighing approximately 200-250 g. Rats were housed at room temperature, fed with standard rat chow with free access to food and water throughout the study. They were housed on in metal cages; five rats in each cage. An adaptation period of one week was allowed before experimental protocol. Experiments were conducted in accordance with guidelines set by the Research Ethics Committee of Benha Faculty of Medicine.

\section{Experimental design}

The animals were randomly divided into 4 groups $(n=8$ rats per group):
Group I. SHAM control group: sham operated control rats received sesame oil orally by gavage daily for 8 weeks.

Group II. OVX group: rats were subjected to ovariectomy at the beginning of the study then administered sesame oil orally by gavage daily for 8 weeks from the day after surgery.

Group III. OVX+E2 group: OVX rats received $17 \mathrm{~b}-$ estradiol (from Sigma Chemicals) $0.5 \mathrm{mg} / \mathrm{kg}$ dissolved in sesame oil daily orally by gavage for 8 weeks from the day after surgery (Ulas and Cay 2010).

Group IV. OVX+ACEI group: OVX rats received captopril (from Epico, Egypt; $5 \mathrm{mg} / \mathrm{kg}$ ) dissolved in water daily orally by gavage for 8 weeks from the day after surgery (Yu et al. 2011).

\section{Experimental procedures}

The rats in the experimental groups were subjected to surgical procedures whether ovariectomy or sham operation. The rats were fasted overnight prior to surgery. All animal dissections were conducted by surgical procedures with aseptic technique. Rats were anesthetized by Thiopental Na (dose $40 \mathrm{mg} / \mathrm{kg}$ ) and injected intramuscularly with antibiotics (penicillin G procaine 40,000 U/kg). After anesthesia, the ventral part of the abdominal region was shaved and then cleaned with ethanol. One small incision $(1 \mathrm{~cm})$ was made through the skin and the muscle wall on the Centre of peritoneal area. The ovaries were then located, and a silk sterile thread was tightly tied around the oviduct, including the ovarian blood vessels. The oviduct was sectioned, and the ovary was removed taking good care in leaving the knot intact. The wound was closed in two layers, i.e. muscle and skin using sterile sutures (Behr et al. 2011).

Sham operated animals were also anesthetized, the skin and muscle layers were opened, the uterus and ovaries were gently manipulated but not excised, and the wound was closed in two layers. After surgery, rats were housed individually for some hours to allow recovery and then re-grouped in their home cages.

\section{Preparation of serum}

Rats were anesthetized then sacrificed after $12 \mathrm{~h}$ overnight fasting. Blood samples were collected from cardiac puncture in dry clean test tubes for separation of serum. Serum was separated by centrifugation at $3000 \mathrm{rpm}$ for $15 \mathrm{~min}$ and was stored at $-20^{\circ} \mathrm{C}$ for measurement of the following:

Serum total calcium (Faulkner1982) and alkaline phosphatase (ALP) activity (Vasiliades 1976) were measured by colorimetric method (Chemroy, Biochemical Trade, Inc. USA) in Beckman Coulter DU-70 spectrophotometer (Beckman Coulter Inc., CA, USA). Serum osteoprotegerin (OPG) was determined by enzyme linked 
immunosorbent assay (ELISA) technique using R\&D Elisa (SorinBiomedica, Eti-System, Denlay Instruments Ltd, England) kit as described by O'Brien et al. (2001). Serum osteocalcin was also measured with osteocalcin (OC) rat ELISA system (Rat Bone Panel3 Millipore, MA, USA) (Netto et al. 2012). Serum receptor activator of nuclear factor kappa B ligand (RANKL) levels were determined by enzyme linked immunosorbent assay (ELISA) technique using R\&D ElIZA (SorinBiomedica, Eti-System, Denlay Instruments Ltd, England) kit as described by Teng et al. (2000). Serum alkaline phosphatase and OC were measured as markers for bone formation. The OPG/RANKL ratio was calculated.

\section{Collection of 24-h urine}

Twenty-four hours before scarification each rat was kept in a special metallic cage with a perforated plate form to calculate urine output starting from 8 a.m. to 8 a.m. next day. A glass funnel was fixed under each cage fitting to the area of its plate form. From this funnel the urine passed to a collecting bottle. Urine samples were collected in dry test tubes and kept at $-20^{\circ} \mathrm{C}$ until being analyzed. Urine samples were collected from all animals to measure urinary hydroxyproline level as a marker for bone resorption (Gallo et al. 2005).

Right femur from each rat was stored in formalin buffer $10 \%$ for image analysis. The left femur from each rat was stored in liquid nitrogen for gene expression of RANKL and OPG.

\section{Image analysis procedure}

Right femur from each rat was embedded in paraffin sections and was stained with Hematoxylin and Eosin (H\&E) for image analysis technique as following; cortical bone thickness was measured by a free hand line tool which is calibrated against a micrometer slide photographed under the same conditions. The trabecular bone area was manually extracted as following; total area of the extracted trabecular bone was measured. Then the empty areas were subtracted according to color variation and the area was measured again. Area fraction was calculated in percent. Mean cortical bone thickness $(\mathrm{CBT})(\mu \mathrm{m})$ and mean trabecular bone density (TBD) (\%) were obtained by measuring 5 fields/slide from 5 slides for each rat. The reading of each animal was considered as one variable (Samir and Malek 2014).

Real-time PCR analyses for $m R N A$ expression of bone OPG and RANKL genes: Total RNA extraction

The metaphyseal portion of the femur was cut and homogenized using a Mixer Mill MM400 (Retsch, Germany) to isolate the mRNA. Total RNA was isolated from $25 \mathrm{mg}$ tissue using total RNA purification kit Jena Bioscience Germany. The concentration and purity of the RNA were determined by measuring the absorbance at $260 \mathrm{~nm}$ and $280 \mathrm{~nm}$. The amount of RANKL and OPG mRNA was determined with ABI Prism 7900HT quantitative real-time PCR (Applied Biosystems, Foster City, CA). The primers were as follows: RANKL (forward, 5'-ACC AGC ATC AAA ATC CCA AG-3', reverse, 5'-TTT GAA AGC CCC AAA GTA CG-3') and OPG (forward, 5'-GTT CTT GCACAG CTT CAC CA-3', reverse, 5'TCTCCAGGAGTGCCATCTCT-3'). PCR amplification was carried out in a $20 \mu \mathrm{l}$ reaction mixture $(2 \mu \mathrm{l}$ of cDNA and $200 \mathrm{nmol} / \mathrm{l}$ primers for OPG and RANKL, respectively, and $1 \mu \mathrm{l}$ SYBR green). The temperature program was as follow:inactivation of reverse transcriptase at $95^{\circ} \mathrm{C}$ for $5 \mathrm{~min}$, followed by 45 -cycles of $95^{\circ} \mathrm{C}$ for $30 \mathrm{~s}, 60^{\circ} \mathrm{C}$ for $1 \mathrm{~min}$, and $72^{\circ} \mathrm{C}$ for $30 \mathrm{~s}$. The specificity of the PCR results was confirmed by dissociation curve analysis. According to the RQ manager program ABI SDS software (ABI 7900), the data are produced as sigmoid shaped amplification plots in which the number of cycle is plotted against fluorescence (when using linear scale). The threshold cycle (CT) serves as a tool for calculation of the starting template amount in each sample. Because the samples of control group and also samples of treated group are used as calibrators, the expression levels are set to 1 . Because the relative quantities of the OPG\&RANKL gene are normalized against the relative quantities of the endogenous control B-actin gene fold expression changes are calculated using the equation $2^{-\Delta \Delta \mathrm{ct}}$ in the study of Alhusseini et al. (2010).

\section{Statistical analysis}

All the data are presented as mean \pm standard deviation (SD). Evaluation of differences between groups was performed using one-way ANOVA with post hoc test (LSD) between groups with SPSS 19.0 software. A $p$ value of less than 0.05 was considered statistically significant.

\section{Results}

Effect of estrogen or captopril on bone markers, serum OPG and RANKL levels in OVX rats

As shown in Table 1, the present work revealed that ovariectomy (Group II) led to a significant increase in serum osteocalcin, alkaline phosphatase activity, urinary hydroxylproline levels and RANKL activity $(p<0.05)$ with a significant decrease in serum calcium and serum OPG levels $(p<0.05)$ when compared to control rats (Group I). 
Table 1. Effect of estrogen or captopril on serum calcium, osteocalcin, alkaline phosphatase activity, urinary hydroxylproline, serum RANKL, serum OPG and OPG/RANKL ratio in OVX rats

\begin{tabular}{lcccc}
\hline & $\begin{array}{c}\text { Group I } \\
\text { (SHAM) }\end{array}$ & $\begin{array}{c}\text { Group II } \\
(\text { OVX) }\end{array}$ & $\begin{array}{c}\text { Group III } \\
\text { (OVX+E2) }\end{array}$ & $\begin{array}{c}\text { Group IV } \\
(\text { OVX+ACEI })\end{array}$ \\
\hline Serum calcium (mg/dl) & $9.43 \pm 0.19$ & $7.86 \pm 0.28^{\mathrm{a}}$ & $9.26 \pm 0.29^{\mathrm{b}}$ & $9.04 \pm 0.23^{\mathrm{ab}}$ \\
Serum osteocalcin (ng/ml) & $4.23 \pm 0.16$ & $6.28 \pm 0.13^{\mathrm{a}}$ & $4.34 \pm 0.18^{\mathrm{b}}$ & $4.24 \pm 0.11^{\mathrm{b}}$ \\
Serum alkaline phosphatase activity (u/l) & $164 \pm 1.25$ & $244.12 \pm 2.59^{\mathrm{a}}$ & $174.75 \pm 1.04^{\mathrm{ab}}$ & $172.38 \pm 2.67^{\mathrm{abc}}$ \\
Urinary hydroxylproline (mg/dl) & $15.4 \pm 0.04$ & $25.7 \pm 0.13^{\mathrm{a}}$ & $16.5 \pm 0.24^{\mathrm{ab}}$ & $15.8 \pm 0.13^{\mathrm{abc}}$ \\
Serum RANKL (pg/ml) & $55.63 \pm 1.4$ & $112 \pm 5.7^{\mathrm{a}}$ & $99.5 \pm 1.2^{\mathrm{ab}}$ & $60.5 \pm 1.4^{\mathrm{abc}}$ \\
Serum OPG (pg/ml) & $15.96 \pm 0.21$ & $8.49 \pm 0.42^{\mathrm{a}}$ & $15.65 \pm 0.21^{\mathrm{b}}$ & $9.06 \pm 0.78^{\mathrm{abc}}$ \\
OPG/RANKL ratio & $0.29 \pm 0.008$ & $0.08 \pm 0.005^{\mathrm{a}}$ & $0.16 \pm 0.005^{\mathrm{ab}}$ & $0.15 \pm 0.009^{\mathrm{ab}}$ \\
\hline
\end{tabular}

Mean \pm SD $(n=8) .{ }^{a}$ Significant difference $(p<0.05)$ compared with control group; ${ }^{b}$ significant difference $(p<0.05)$ compared with group II; ${ }^{c}$ significant difference $(p<0.05)$ compared with group III; OPG, osteoprotegerin; RANKL, receptor activator of nuclear factorkappa B ligand; OVX, ovariectomized; ACEI, angiotensin converting enzyme inhibitor; E2, estrogen.

Whereas, OVX rats treated with E2 (Group III) showed a significant decrease in serum osteocalcin, alkaline phosphatase activity, urinary hydroxylproline levels and RANKL activity $(p<0.05)$ with a significant increase in serum calcium and OPG levels $(p<0.05)$ when compared to OVX group (Group II). In addition OVX rats treated with captopril (Group IV) showed a significant decrease in serum osteocalcin, alkaline phosphatase activity, urinary hydroxylproline levels and RANKL activity $(p<0.05)$ with a significant increase in serum calcium $(p<0.05)$ and non-significant increase in OPG levels when compared to Group II. As well as there was a significant decrease $(p<0.05)$ in alkaline phosphatase activity and urinary hydroxylproline level in Group IV when compared with Group III. Concerning OPG/RANKL ratio there was a significant decrease $(p<0.05)$ in OVX non treated rats and a significant increase $(p<0.05)$ in OVX rats treated with E2 or captopril. Group III and Group IV showed significant increase in alkaline phosphatase activity, urinary hydroxylproline levels and RANKL activity $(p<0.05)$ with a significant decrease $(p<0.05)$ in OPG/RANKL ratio with a significant decrease $(p<0.05)$ in serum calcium and OPG and a significant decrease $(p<0.05)$ in serum RANKL when compared with Group I.
Effect of estrogen or captopril on mean cortical bone thickness $(C B T ; \mu \mathrm{m})$ and mean trabecular bone density (TBD; \%) in OVX rats

As shown in Table 2 and Fig. 1, the present work revealed that ovariectomy (Group II) led to a significant decrease $(p<0.05)$ in CBT and TBD when compared to control rats (Group I). Whereas, OVX rats treated with E2 (Group III) and OVX rats treated with captopril (Group IV) showed a significant increase $(p<0.05)$ in CBT and TBD. While Group III and Group IV showed a significant decrease in CBT and TBD when compared with Group I.

Effect of E2 or captopril on OPG $m R N A$ expression and RANKL $m R N A$ expression in OVX rats by real-time PCR analyses

As shown in Table 3, the present work revealed that ovariectomy (Group II) led to a significant decrease $(p<0.05)$ in OPG mRNA expression and a significant increase $(p<0.05)$ in RANKL mRNA expression when compared to control rats (Group I). Whereas, OVX rats treated with E2 (Group III) showed a significant increase $(p<0.05)$ in OPG mRNA expression and a significant decrease $(p<0.05)$ in RANKL mRNA expression

Table 2. Effect of estrogen or captopril on CBT and TBD of rat femur bone by image analysis

\begin{tabular}{lcccc}
\hline & $\begin{array}{c}\text { Group I } \\
(\text { SHAM })\end{array}$ & $\begin{array}{c}\text { Group II } \\
(\text { OVX })\end{array}$ & $\begin{array}{c}\text { Group III } \\
(\text { OVX+E2 })\end{array}$ & $\begin{array}{c}\text { Group IV } \\
(\text { OVX+ACEI })\end{array}$ \\
\hline CBT $(\mu \mathrm{um})$ & $61.06 \pm 1.9$ & $23.48 \pm 1.43^{\mathrm{a}}$ & $57.91 \pm 1.01^{\mathrm{ab}}$ & $55.75 \pm 1.04^{\mathrm{abc}}$ \\
TBD $(\%)$ & $66.9 \pm 1.36$ & $33.38 \pm 1.06^{\mathrm{a}}$ & $42.38 \pm 1.06^{\mathrm{ab}}$ & $61.13 \pm 0.83^{\mathrm{abc}}$ \\
\hline
\end{tabular}

Mean \pm SD $(n=8) .{ }^{a}$ Significant difference $(p<0.05)$ compared with control group; ${ }^{b}$ significant difference $(p<0.05)$ compared with group II; ${ }^{c}$ significant difference $(p<0.05)$ compared with group III. CBT, cortical bone thickness; TBD, trabecular bone density; OVX, ovariectomized; ACEI, angiotensin converting enzyme inhibitor; E2, estrogen. 

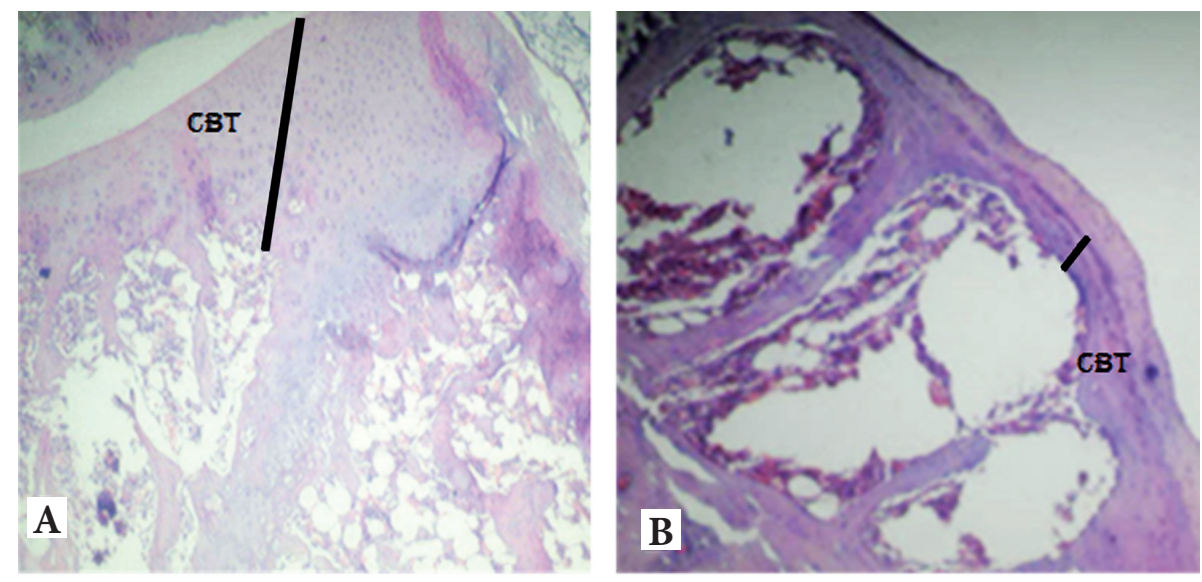

Figure 1. Effect of estrogen or captopril on CBT and TBD\% of rat femur bone by image analysis. A. The photomicrograph of a section in the femur of control normal rats showing mean cortical bone thickness and mean trabecular bone density. $\mathrm{H} \& \mathrm{E}$, magnification $\times 100$. B. The photomicrograph of a section
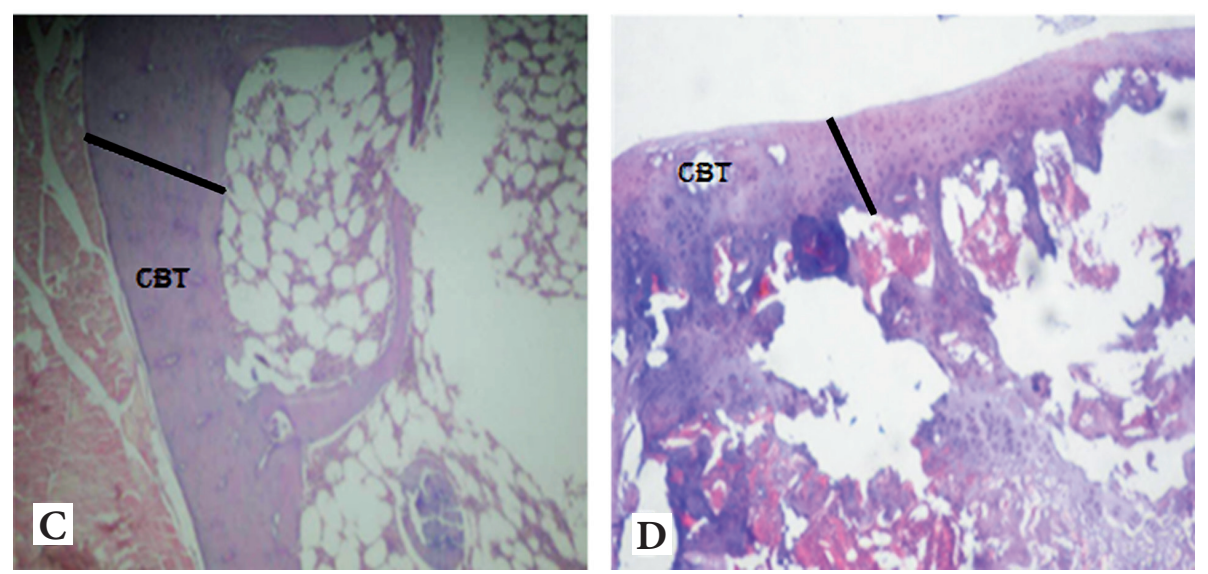
in the femur of OVX rats showing mean cortical bone thickness (CBT) and mean trabecular bone density. $\mathrm{H} \& \mathrm{E}$, magnification $\times 100$. C. The photomicrograph of a section in the femur of OVX rats treated with E2 showing mean cortical bone thickness and mean trabecular bone density. $\mathrm{H} \& \mathrm{E}$, magnification $\times 100$. D. The photomicrograph of a section in the femur of OVX rats treated with ACEI, captopril showing mean cortical bone thickness and mean trabecular bone density. $\mathrm{H} \& \mathrm{E}$, magnification $\times 100$.

as well as OVX rats treated with captopril (Group IV) showed a significant decrease $(p<0.05)$ in RANKL mRNA expression with non-significant increase in OPG mRNA expression when compared with OVX non-treated rats. The expression of RANKL mRNA in OVX rats treated with captopril is significantly decreased $(p<0.05)$ than its expression in OVX treated with E2. Group III and Group IV showed a significant decrease $(p<0.05)$ in OPG mRNA expression when compared with a significant increase $(p<0.05)$ of RANKL mRNA expression in Group III when compared with Group I.

\section{Discussion}

Captopril (ACEI) is used widely for treatment of hypertension that commonly coexists with osteoporosis in menopausal female so this study was designed to investigate the effect of ACEI on bone loss induced by ovariectomy. There are controversies on the beneficial effects of ACEI on bone and its effect on OPG/RANKL signaling to modulate bone metabolism. To the best of our knowledge, it is the first study which investigates the effect of ACEI on OPG/ RANKL ratio

Table 3. Effect of E2 or captopril on OPG mRNA expression and RANKL mRNA expression in rat femur bone by Real-time PCR analyses

\begin{tabular}{lcccc}
\hline & $\begin{array}{c}\text { Group I } \\
\text { (SHAM) }\end{array}$ & $\begin{array}{c}\text { Group II } \\
\text { (OVX) }\end{array}$ & $\begin{array}{c}\text { Group III } \\
(\text { OVX+E2) }\end{array}$ & $\begin{array}{c}\text { Group IV } \\
(\text { OVX+ACEI) }\end{array}$ \\
\hline OPG mRNA level & $1.46 \pm 0.11$ & $0.66 \pm 0.04^{\mathrm{a}}$ & $0.82 \pm 0.02^{\mathrm{ab}}$ & $0.68 \pm 0.03^{\mathrm{ac}}$ \\
RANKL mRNA level & $0.8 \pm 0.09$ & $1.49 \pm 0.08^{\mathrm{a}}$ & $1.18 \pm 0.12^{\mathrm{ab}}$ & $0.88 \pm 0.08^{\mathrm{bc}}$ \\
\hline
\end{tabular}

The mRNA expressed by Log10 relative units of relative quantitation (RQ). Mean \pm SD $(n=8) .{ }^{\text {a }}$ Significant difference $(p<0.05)$ compared with control group; ${ }^{b}$ significant difference $(p<0.05)$ compared with group II; ${ }^{c}$ significant difference $(p<0.05)$ compared with group III. OPG, osteoprotegerin; RANKL, receptor activator of nuclear factor-kappa B ligand; OVX, ovariectomized; ACEI, angiotensin converting enzyme inhibitor; E2, estrogen. 
in ovariectomized rats (osteoporosis caused by estrogen deficiency).

Our data showed that ovariectomy led to a significant decrease in the plasma $\mathrm{Ca}^{2+}$ level 8 weeks after ovariectomy in the OVX rats when compared with the SHAM operated control group as shown in Table 1. These results are in agreement with Mattix-Kramer et al. (2003) who reported that ovariectomized rats had impaired $\mathrm{Ca}^{2+}$ balance that could have contributed to ovariectomy-induced osteoporosis. Menopause is associated with impaired intestinal $\mathrm{Ca}^{2+}$ absorption that could be due to the resistance of the gastrointestinal system to the action of 1,25-dihydroxyvitamin $\mathrm{D}$ as the estrogen has been shown to modulate the end organ effect of 1,25-dihydroxyvitamin D on intestinal calcium absorption (Gennari et al. 1990). Furthermore, menopause is associated with increased renal excretion of calcium as the estradiol increases renal tubular $\mathrm{Ca}^{2+}$ reabsorption (Dick et al. 2005). Also, the OVX rats exhibited a significant increase in bone turnover as evidenced by a significant increase in both bone resorption that was manifested by a significant increase in urine hydroxyproline level and increased bone formation that was manifested by a significant increase in plasma osteocalcin and ALP levels compared to SHAM operated rats as shown in Table 1, this is in accordance with a previous study (Mukherjee et al. 2006) who found an increase in both markers in OVX rats. E2 deficiency up-regulates the production and action of several cytokines such as TNF alpha and RANKL that increases bone resorption leading to an increase in bone resorption markers (Vural et al. 2006). The question that arises now is how E2 deficiency induced by ovariectomy can induce an increase in bone formation? It is well known that bone formation occurs only at sites of previous resorption in remodeling bone, where the appropriate number of mature osteoblasts is thought to be controlled by growth factors that are released from the bone matrix during its resorption by osteoclast. So, the increase in bone resorption in OVX rats should be associated with an increase in bone formation. However, the quantity of bone formed is lower than the quantity of bone resorbed which results in a net bone loss and increased risk of osteoporosis (Lofman et al. 2005).

Moreover, femurs of the OVX rats showed eroded cavities with widened bone marrow spaces indicating increased bone resorption. The mean CBT and TBD \% were both significantly decreased in OVX rats compared to SHAM rats as shown in Table 2 and Figure 1. These results are in accordance with Grassi et al. (2006) who linked E2 deficiency to an accelerated bone remodeling, where bone resorption outpaced bone formation. As well as Faitelson et al. (2012) reported that OVX rats develop endothelial dysfunction of microcirculation in bone tissue, leading to a significant deterioration in bone blood flow, which in turn leads to a thinning of bone trabeculae and micro-fractures in them, and therefore osteoporosis.

In our study, E2 supplementation in rats by a dose $0.5 \mathrm{mg} / \mathrm{kg} /$ day for 8 weeks prevented the decrease in the plasma Ca ${ }^{2+}$ and decreased bone markers compared with the OVX rats as shown in Table 1 and Figure 1 which is in accordance with studies done on OVX rats (Mukherjee et al. 2006) and postmenopausal women (Vural et al. 2006). It is well established that activation of E2 receptors in osteoblasts induces their anabolic activities and reduces the pathway by which osteoblasts can activate osteoclasts (Lerner 2006). Also, E2 promotes its osteoprotective effect due to its antioxidant action (Padayatty et al. 2003). The enhanced effects of E2 supplementation are assured by the significant elevation of CBT and TBD as shown in Table 2 and Figure 1.

In addition, our study revealed that there was a significant decrease in serum OPG level with significant increase in RANKL level together with significant decrease in OPG/ RANKL ratio as shown in Table 1 and there was significant increase in mRNA expression of RANKL with significant decrease in mRNA expression of OPG in the femur bone of non-treated OVX group when compared with control group as shown in Table 3. E2 supplementation showed a significant increase in serum OPG with the decrease in RANKL together with a significant increase in OPG/RANKL ratio and this supported by a significant increase in OPG mRNA expression and a significant decrease in RANKL mRNA expression when compared to the OVX non-treated group as shown in Table 1 and 3. These results suggest that E2 may produce its anti-resorptive effect through increasing production of OPG, one of the local factors which markedly inhibit bone resorption and osteoclasts differentiation. These results run parallel to that of Hashish et al. (2007). Also, it decreases the level of RANKL that can activate mature osteoclasts. These results are in agreement with that of Bord et al. (2003) who documented that human osteoblasts respond to low dose estrogen treatment with repression of RANKL while maintaining OPG expression support that modulating this mechanism may be a key in estrogen effects on osteoclast differentiation in human cells as well. The changes in the OPG/RANKL ratio are the direct effect of estrogen modulation on either or both gene expressions or through estrogen modulation of cytokines and other growth factors.

E2 binds to receptors on the osteoblasts and directly increases OPG production. The increase in OPG decreases the interaction of RANKL with RANK and consequently reduces osteoclastic bone resorption, so estrogen deficiency as seen in OVX rats leads to decrease in the production of OPG thus facilitates the RANKL-RANK ligand interaction and so facilitates the differentiation of the osteoclast precursor into a mature osteoclast (Tulay 2015). 
The OVX rats received the ACEI, captopril, by a dose $5 \mathrm{mg} / \mathrm{kg} /$ day for 8 weeks showed a significant decrease in serum $\mathrm{Ca}^{2+}$ and decrease in bone markers when compared with the OVX non-treated rats as shown in Table 1. This is in accordance with several studies (Rejnmark et al. 2006; Ghosh and Majumdar 2014) which revealed that the captopril has a protective effect on the bone and that patients treated with ACEI showed an increase in bone mineral density and decrease in fracture risk.

This study revealed a significant decrease in serum RANKL and non-significant change in serum OPG with a significant increase in OPG/RANKL ratio in OVX rats treated with captopril as shown in Table 1. These results supported by a significant decrease in RANKL mRNA expression with non-significant increase in OPG mRNA expression when compared with OVX non-treated group as shown in Table 3. These results suggest that captopril may produce its bone protective effect by increasing OPG/RANKL ratio through decreasing RANKL mRNA expression. These results are similar to that of Shuai et al. (2015) who evidenced that the role of local RAS is related to bone mineral density in glucocorticoid-induced osteoporosis patients, and suggested that local RAS might influence OPG/RANKL signaling to modulate bone metabolism. Only one study showed that inhibition of the RAS caused non-significant changes in circulating OPG levels in hypertensive patients (Oz et al. 2015). In addition, AngII significantly induced the expression of receptor activator of NF- $\mathrm{KB}$ ligand (RANKL) in osteoblasts, leading to the activation of osteoclasts, whereas these effects were completely blocked by an AngII type 1 receptor blocker (Kaneko et al. 2011) and Quantitative RT-PCR using RNA isolated from the tibia and femur of mice lacking the gene encoding the major Ang II receptor isoform, AngII type 1A receptor (AT1a) revealed that the OPG/RANKL ratio was increased (Gebru et al. 2013). While, in the contrary to the above mentioned beneficial effects of ACEI on the bone, several studies indicated that ACEI use did not change the rate and risk of fracture and even led to greater bone loss (Masunari et al. 2008; Kwok et al. 2012; Zhang et al. 2012; Kang et al. 2013). They explained the role of ACEI on the regulation of kinin-kallikrein system within which bradykinin can stimulate bone resorption and reduce BMD (Zhang et al. 2012). Another possible reason comes from using different types of the ACEI as they differ in their distribution and affinity for tissue-bound ACE (Morishita et al. 1993).

In the current study we showed that ACEI has more significant effect on decreasing bone markers than E2 in OVX rats. This can be explained by a significant increase in OPG/ RANKL ratio in rats treated with captopril than E2 treated rats in spite of a significant increase in serum OPG levels in E2 treated group than captopril-treated group, but the decrease in RANKL level in captopril treated group is more than the increase in OPG level in the E2 treated group.
The limitation of our study is its short duration, as 8 weeks are not enough to detect the complications of estrogen and ACEI and comparing them. So we recommend doing further studies on more prolonged durations.

\section{Conclusion}

In OVX rats, an altered modulation of the OPG/RANKL system resulting in increased RANKL and decreased OPG in peripheral blood, could contribute to the bone loss characteristic and the generation of osteoporosis. Changes of ratio of OPG/RANKL induced by either E2 or ACEI might be a protective mechanism against the accelerated bone loss in OVX rats. Moreover ACEI treatment has more protective effect than E2 by its ability to increase OPG/RANKL ratio than E2 treatment, so we recommend ACEI for postmenopausal females suffering from hypertension as a treatment of choice for its benefits in both hypertension and osteoporosis as they commonly coexist together.

\section{References}

Alhusseini N. F., Odaa M. M., Mohamed M. A., Abd El Wahab W. B., Hasan A. A. (2010): Expression of adiponectin receptors in human placenta and its possible implication in gestational diabetes. Am. J. Biochem. Biotechnol. 6, 136-140 http://dx.doi.org/10.3844/ajbbsp.2010.136.140

Donmez B. O., Ozdemir S., Sarikanat M., Yaras N., Koc P., Demir N., Karayalcin B., Oguz N. (2012): Effect of angiotensin II type 1 receptor blocker on osteoporotic rat femurs. Pharmacol. Rep. 64, $878-888$ http://dx.doi.org/10.1016/S1734-1140(12)70882-4

Behr G. A., Schnorr C. E., Moreira J. C. (2011): Increased blood oxidative stress in experimental menopause rat model: the effects of vitamin A low-dose supplementation upon antioxidant status in bilateral ovariectomized rats. Fundam. Clin. Pharmacol. 26, 235-249 http://dx.doi.org/10.1111/j.1472-8206.2010.00923.x

Bord S., Ireland D. C., Beavan S. R., Compston J. E. (2003): The effects of estrogen on osteoprotegerin, RANKL, and estrogen receptor expression in human osteoblasts. Bone 32,136-141 http://dx.doi.org/10.1016/S8756-3282(02)00953-5

Coetzee M., Kruger M. C. (2004): Steoprotegerin-receptor activator of nuclear factor-[kappa]B ligand ratio: A new approach to osteoporosis treatment. South Med. J. 97, 506-511 http://dx.doi.org/10.1097/00007611-200405000-00018

Dick I. M., Devine A., Beilby J., Prince R. L. (2005): Effects of endogenous estrogen on renal calcium and phosphate handling in elderly women. Am. J. Physiol. Endocrinol. Metab. 288, 430-435 http://dx.doi.org/10.1152/ajpendo.00140.2004

Faulkner W. R., Meites S. (1982): Selected Methods for the Small Clinical Chemistry Laboratory. pp. 126, American Association for Clinical Chemistry, Washington

Gallo D., Zannoni G. F., Apollonio P. Martinelli E., Ferlini C., Passetti G., Riva A., Morazzoni P., Bombardelli E., Scambia 
G. (2005): Characterization of the pharmacologic profile of a standardized soy extract in the ovariectomized rat model of menopause: effects on bone, uterus, and lipid profile. Menopause 12, 589-600 http://dx.doi.org/10.1097/01.GME.0000156348.61767.D5

Gennari C., Agnusdei D., Nardi P., Civitelli R. (1990): Estrogen preserves a normal intestinal responsiveness to 1,25-dihydroxyvitamin D3 in oophorectomized women. J. Clin. Endocrinol. Metab. 71, 1288-1293

http://dx.doi.org/10.1210/jcem-71-5-1288

Ghosh M., Majumdar S. R. (2014): Antihypertensive medications, bone mineral density, and fractures: a review of old cardiac drugs that provides new insights into osteoporosis. Endocrine 46, 397-405 http://dx.doi.org/10.1007/s12020-014-0167-4

Grassi F., Fan X., Rahnert J., Weitzmann M. N., Pacifici R., Nanes M. S., Rubin J. (2006): Bone re/modeling is more dynamic in the endothelial nitric oxide synthase(-/-) mouse. Endocrinology 147, 4392-4399 http://dx.doi.org/10.1210/en.2006-0334

Hashish A. H., Bayoumy A. M., Maklad H. M., Nassar S. Z., Sharara G. M. (2007): Effect of estrogen and N-acetyl cysteine on bone remodling and bone cytokine osteoprotegrin on ovariectomized rats. Alexandria Bulletin 43, 4

Hofbauer L. C., Heufelder A. E. (2001): Role of receptor activator of nuclear factor-kappaB ligand and osteoprotegerin in bone cell biology. J. Mol. Med. (Berl.) 79, 243-253 http://dx.doi.org/10.1007/s001090100226

Kaczmarczyk-Sedlak I., Zych M., Rotko K., Sedlak L. (2012): Effects of thalidomide on the development of bone damage caused by prednisolone in rats. Pharmacol. Rep. 64, 386-395 http://dx.doi.org/10.1016/S1734-1140(12)70779-X

Kaneko K., Ito M., Fumoto T., Fukuhara R., Ishida J., Fukamizu A, Ikeda K. (2011): Physiological function of the angiotensin ATla receptor in bone remodeling. J. Bone Miner. Res. 26, 2959-2966 http://dx.doi.org/10.1002/jbmr.501

Kang K. Y., Kang Y., Kim M., Kim Y., Yi H., Kim J., Jung H. R., Park S. H., Kim H. Y., Ju J. H., Hong Y. S. (2013): The effects of antihypertensive drugs on bone mineral density in ovariectomized mice. J. Korean Med. Sci. 28, 1139-1144

http://dx.doi.org/10.3346/jkms.2013.28.8.1139

Kwok T., Leung J., Zhang Y. F., Bauer D., Ensrud K. E., BarrettConnor E., Leung P. C. (2012): Osteoporotic fractures in Men(MrOS) research group. Does the use of ACE inhibitorsor angiotensin receptor blockers affect bone loss in older men? Osteoporos Int. 23, 2159-2167

http://dx.doi.org/10.1007/s00198-011-1831-7

Lerner U. H. (2006): Bone remodeling in post-menopausal osteoporosis. J. Dent. Res. 85, 584-595 http://dx.doi.org/10.1177/154405910608500703

Löfman O., Magnusson P., Toss G., Larsson L. (2005): Common biochemical markers of bone turnover predict future bone loss: a 5-year follow-up study. Clin. Chim. Acta 356, 67-75 http://dx.doi.org/10.1016/j.cccn.2004.12.014

Masunari N., Fujiwara S., Nakata Y., Furukawa K., Kasagi F. (2008): Effect of angiotensin converting enzyme inhibitor and benzodiazepine intake on bone loss in older Japanese. Hiroshima J. Med. Sci. 57, 17-25
Mattix Kramer H. J., Grodstein F., Stampfer M. J., Curhan G. C. (2003): Menopause and postmenopausal hormone use and risk of incident kidney stone. J. Am. Soc. Nephrol. 14, 1272-1277 http://dx.doi.org/10.1097/01.ASN.0000060682.25472.C3

Mohy Taha: Prevalence of osteoporosis in Middle East systemic literature review. 10th ECOO, April 2011

Morishita R., Higaki J., Nagano M., Nakamura F., Tomita N., Zhao Y., Mikami H., Miyazaki M., Ogihara T. (1993): Discrepancy between renin mRNA and plasma renin level in angiotensinconverting enzyme inhibitor-treated rats. Clin. Exp. Pharmacol. Physiol. 20, 15-20 http://dx.doi.org/10.1111/j.1440-1681.1993.tb01497.x

Mukherjee M., Das A. S., Das D., Mukherjee S., Mitra S., Mitra C. (2006): Effects of garlic oil on postmenopausal osteoporosis using ovariectomized rats: comparison with the effects of lovastatin and 17b-estradiol. Phytother. Res. 20, 21-27 http://dx.doi.org/10.1002/ptr.1795

Muthusami S., Ramachandran I., Muthusamy B., Vasudevan G., Prabhu V., Subramaniam V., Jagadeesan A., Narasimhan S. (2005): Ovariectomy induces oxidative stress and impairs bone antioxidant system in adult rats. Clin. Chim. Acta 360, 81-86 http://dx.doi.org/10.1016/j.cccn.2005.04.014

Netto C. C., Vieira V. C., Marinheiro L. P., Agellon S., Weiler H., Marostica M. R. Jr. (2012): Are skeletally mature female rats a suitable model to study osteoporosis? Arq. Bras. Endocrinol. Metabol. 56, 259-264 http://dx.doi.org/10.1590/S0004-27302012000400007

O’Brien E. A., Williams J. H., Marshall M. J. (2001): Osteoprotegerin is produced when prostaglandin synthesis is inhibited causing osteoclasts to detach from the surface of mouse parietal bone and attach to the endocranial membrane. Bone 28, 208-214 http://dx.doi.org/10.1016/S8756-3282(00)00431-2

Oz H., Gavish D., Hass A., Shargorodsky M. (2015): Effect of angiotensin II receptor blockers, candesartan, on osteoprotegerin level in hypertensive patients: Link between bone and RAAS. J. Renin Angiotensin Aldosterone Syst. 16, 547-552 http://dx.doi.org/10.1177/1470320314566017

Padayatty S. J., Katz A., Wang Y., Eck P., Kwon O., Lee J. H., Chen S., Corpe C., Dutta A., Dutta S. K., Levine M. (2003): Vitamin $\mathrm{C}$ as an antioxidant: evaluation of its role in disease prevention. J. Am. Coll. Nutr. 22, 18-35 http://dx.doi.org/10.1080/07315724.2003.10719272

Rajkumar D. S., Faitelson A. V., Gudyrev O. S., Dubrovin G. M., Pokrovski M. V., Ivanov A. V. (2012): Comparative evaluation of Enalapril and Losartan in pharmacological correction of experimental osteoporosis and fractures of its background. Orthop. Muscul. Syst. 1-3

Rejnmark L., Vestergaard P., Mosekilde L. (2006): Treatment with beta-blockers, ACE inhibitors, and calcium-channel blockers is associated with a reduced fracture risk: a nationwide casecontrol study. J. Hypertens. 24, 581-589 http://dx.doi.org/10.1097/01.hjh.0000203845.26690.cb

Riggs B. L., Khosla S., Melton L. J. 3rd (2002): Sex steroids and the construction and conservation of the adult skeleton. Endocr. Rev. 23, 279-302 http://dx.doi.org/10.1210/edrv.23.3.0465

Rossouw J. E., Anderson G. L., Prentice R. L. (2002): Risks and benefits of estrogen plus progestin in healthy postmenopausal 
women: principal results from the Women's Health Initiative randomized controlled trial. JAMA 288, 321-333 http://dx.doi.org/10.1001/jama.288.3.321

Samir S. M., Malek H. A. (2014): Effect of cannabinoid receptors 1 modulation on osteoporosis in a rat model of different ages. J. Physiol. Pharmacol. 65, 687-694

Shuai B., Yang Y. P., Shen L., Zhu R., Xu X. J., Ma C., Lv L., Zhao J., Rong J. H. (2015): Local renin-angiotensin system is associated with bone mineral density of glucocorticoid-induced osteoporosis patients. Osteoporosis International 26, 1063-1071 http://dx.doi.org/10.1007/s00198-014-2992-y

Teng Y. T., Nguyen H., Gao X., Kong Y. Y., Gorczynski R. M., Singh B., Ellen R. P., Penninger J. M. (2000): Functional human T-cell immunity and osteoprotegerin ligand control alveolar bone destruction in periodontal infection. J. Clin. Invest. 106, 59-67 http://dx.doi.org/10.1172/JCI10763

Torres A. Y. P., Flores M. V., Orozco L., Cruz R. V. (2013): Molecular aspects of bone remodeling. In: Topics in Osteoporosis. (Ed. Flores M. V.), pp. 1-27, InTech

Tulay Okman-Kilic (2015): Estrogen deficiency and osteoporosis. In: Advances in Osteoporosis. (Ed. Yannis Dionyssiotis), pp. 7-18, InTech http://dx.doi.org/10.5772/59407

Ulas M., Cay M. (2010): The effects of 17b-estradiol and vitamin E treatments on oxidative stress and antioxidant levels in brain cortex of diabetic ovariectomized rats. Acta Physiol. Hung. 97, 208-215
http://dx.doi.org/10.1556/APhysiol.97.2010.2.7

Vasiliades J. (1976): Reaction of alkaline sodium picrate with creatinine. Kinetics and mechanism of formation of the mono- creatinine picrate acid complex. Clin. Chem. 22, 1664-1671

Vural P., Akgul C., Canbaz M. (2006): Effects of hormone replacement therapy on plasma pro-inflammatory and antiinflammatory cytokines and some bone turnover markers in postmenopausal women. Pharmacol. Res. 54, 298-302 http://dx.doi.org/10.1016/j.phrs.2006.06.006

Gebru Y., Diao T. Y., Pan H., Mukwaya E., Zhang Y. (2013): Potential of RAS inhibition to improve metabolic bone disorders. Biomed. Res. Int. 2013, 932691 http://dx.doi.org/10.1155/2013/932691

Liu Y. Y., Yao W. M., Wu T., Xu B. L., Chen F., Cui L. (2011): Captopril improves osteopenia in ovariectomized rats and promotes bone formation in osteoblasts. J. Bone Miner. Metab. 29, 149-158 http://dx.doi.org/10.1007/s00774-010-0209-9

Zhang Y. F., Qin L., Leung P. C., Kwok T. C. (2012): The effect of angiotensin-converting enzyme inhibitor use on bone loss in elderly Chinese. J. Bone Miner. Metab. 30, 666-673 http://dx.doi.org/10.1007/s00774-012-0363-3

Received: October 23, 2015

Final version accepted: April 6, 2016

First published online: September 9, 2016 